\title{
El hermano mayor, reflexiones sobre el legado uni- versal de Ricardo Palma
}

\author{
Luis Del Río Donoso \\ Universidad de la Soborne de París \\ portedespoetes@noos.fr
}

\section{Resumen}

Breve biografia del político, diplomático, escritor y tradicionista Ricardo Palma, considerando el entorno socio cultural, el Perú y America Latina, en la segunda mitad del siglo XIX, períodos formativos de este escritor, la formación militar de marino, de político, la influencia de su pertenencia a la logia Masónica Concordia, pero principalmente su formación intelectual en Valparaiso Chile, el contacto y el compartir con intelectuales de este país. La importancia del papel que cumplió como Director de la Biblioteca Nacional, luego de la Guerra del Pacifico, tarea que lo convirtió para honra suya en el Bibliotecario Mendigo. Para finalizar se señala la importancia de su trabajo intelectual al recopilar la lengua popular y enriquecer el léxico del castellano, en lo que hoy conocemos como enfoque pluricultural.

Palabras clave: Ricardo Palma. siglo XIX, Logia Masónica Concordia, Guerra del Pacífico, Biblioteca Nacional.

\begin{abstract}
Brief biography of politician, diplomat, writer and traditionalist Ricardo Palma, considering the socio-cultural environment, Peru and Latin America, in the second half of the nineteenth century, formative periods of this writer, military training of sailor, politician, the influence of his membership in the Masonic Concordia lodge, but mainly his intellectual formation in Valparaiso Chile and the contact and sharing with intellectuals from this country. The importance of the role he fulfilled as Director of the National Library, after the War of the Pacific, a task that made him his honor in the Beggar Librarian. Finally, he points out the importance of his intellectual work in compiling the popular language and enriching the lexicon of Spanish, from what we now know as a pluricultural approach.
\end{abstract}

Keywords: Ricardo Palma, 19th Century, Masonic Concordia lodge, War of Pacific, National Library. 
Luis Del Río Donoso, Doctorado en Historia y en Máster en Literatura, en la Universidad de la Sorbona. Profesor de literatura hispanófona en liceos y algunas Universidades en Francia, Europa y América Latina. Fundador y creador de la revista bilingüe La Puerta de los Poetas. Editory conferencista, desarrolla proyectos multiculturales en Francia, Europa y América Latina. 


\section{Introducción}

Para un poeta o escritor, la relación entre el hombre y la sociedad no posee otras fronteras que su conciencia. Por su alfabeto, escrito u oral, dialoga con un espíritu creador a fin de simbolizar la cosmogonía de sus ideas y pensamientos. Cada palabra es el resultado de una profunda mirada sobre su propio sentir, y sobre los innumerables testimonios, los cuales son huellas de sus vivencias. Confrontado al misterio de los días, interrogaciones, o realidades que muchas veces sobrepasan la ficción, su sensibilidad lo conduce a tomar posiciones y decisiones, sea en metáforas, prosa o versos. Nos atrevemos entonces a definir sin temor que todo poeta o escritor es un trabajador de sus raíces, iluminado por los reflejos de su memoria personal y colectiva. Y, en particular, por esas voces visibles o invisibles, sin distingos de geografías, que habitan en la piel de la sabiduría humana. «Quien escribe un poema, expresaba el Nobel Joseph Brodsky, lo escribe sobre todo porque la escritura de versos es un extraordinario acelerador de la conciencia, del pensamiento, de la comprensión del universo» ${ }^{1}$.

Siguiendo el fondo de este pensamiento, me acerco a la vida y obra de Ricardo Palma, más bien con asombro ante la singular diversidad de su existencia y de su creación literaria. Además, con profundo respeto por lo que me parece es la trascendencia de su legado: recordarnos los valores que sustentan lo humano, la variedad en la unidad de todo lenguaje, y su particular visión que trasciende desde la peruanidad hacia el espíritu universal.

A fin de corresponder con el título del presente Encuentro Internacional Re-Visión de las Tradiciones, decido re-visitar parte de la existencia del hermano mayor, y reflexionar al amparo de

1 Joseph Brodsky, discurso de aceptación del Premio Nobel de Literatura, 1987: http://diariosderesistencia.blogspot.pe/2017/02/del-dolor-y-la-razon.html 
sus hechos de vida, donde resaltan los ancestrales valores de humanidad, fuentes que influyeron en su personalidad, carácter, creación y acción, durante sus prolíferos ochenta y seis años de vida. Y que hoy, a casi un siglo de su partida ${ }^{2}$, mantienen su fuerza y vigor en la conciencia de las nuevas generaciones del Perú, nuestra América Latina y otros continentes. El método de investigación es sumario, cronológico, con aportes de experiencias personales.

\section{Primera mirada: Adolescencia. Poesía. Hermandad.}

Como sabemos por experiencia, entre infancia y adolescencia se revelan las primeras sensaciones de ser y estar en un mundo que no nos pertenece. En formación permanente, los cambios físicos, síquicos y fisiológicos, aumentan ese sentimiento de soledad. No hay excepciones. Más tarde o más temprano, entre 10 y 15 años, comenzamos a tomar conciencia de lo que nos rodea, y surgen interrogantes, preguntas o silencios, ante la incógnita de encontrar respuestas que en determinadas ocasiones no llegan.

La búsqueda de una identidad, más allá del cómo los demás la ven, se perfila desde temprana edad en Manuel Ricardo Palma Carrillo. En distintas biografías ${ }^{3}$ se hace notar la condición humilde de sus padres, su mestizaje, y la pronta separación del matrimonio. No es difícil deducir la orfandad de un niño de nueve años y los derivados afectivos que eso conlleva, sobre todo ante la ausencia de la madre.

Por lo señalado, nos parece lógica la aceleración de su madurez, abrigada por su dedicación a la lectura y a la escritura. Los libros motivan su imaginación, despiertan sueños, abren las ventanas de sus pupilas al tenor de viajes, personajes o

2 Falleció el 6 de Octubre de 1919. Distrito de Miraflores, Lima, Perú.

3 Pueden visualizar las principales en: http://es.wikipedia.org/wiki/Ricardo Palma 
geografías que se representan sin límites y van a influenciar sus primeros escritos. Sin duda, desde su prematura adolescencia asume el verdadero valor de los otros lenguajes, esos susurros y voces que fueron tejiendo su espíritu sensible e interrogador. Comprendemos de esta manera el por qué, a los quince años, comienza una carrera literaria que lo acompañará toda su vida. Y no es por casualidad que sus primeros textos sean poemas. Esto hace parte de su singular respuesta frente a una sociedad en permanente ebullición y en contradicción con lo romántico de sus ideales. Al contrario, la pertenencia al grupo La bohemia de mi tiempo, con jóvenes de la época, le proporciona un espacio de intercambio sobre temas de toda índole, indispensable en su formación social y política. Comienza a incursionar en el periodismo, obras de teatro, crónicas y relatos, género histórico donde destacan sus primeros textos de lo que será su libro más difundido y leído en el país: Tradiciones Peruanas ${ }^{4}$.

Multifacético, perspicaz, observador y atento a sonidos, ritmos y expresiones del verbo popular y educado de su pueblo, Ricardo Palma llega a recrear un estilo de escritura donde poesía, pensamiento e ironía van de la mano. Cito una parte de su poema Poesía:

Es preciso no estar en sus cabales,

Para que un hombre aspire a ser poeta,

Pero en fin, es sencilla la receta.

Forme usted líneas de medidas iguales

Luego en fila las junta

Poniendo consonantes en la punta".

-¿Y en el medio?- "¿en el medio?

iEse es el cuento!

Hay que poner talento. (1910: 180)

4 www.urp.edu.pe/relacionesuniversitarias/tradiciones-peruanas.html 
Si meditamos sobre el hecho que este poema lo escribe en la época de su adolescencia, podemos deducir que llevaba consigo un talento y sensibilidad innatos. Ellos comienzan a manifestarse a la luz de sus lecturas en los selectos colegios donde estudia ${ }^{5}$. Y luego, en la práctica de la escritura metafórica, abrazando sus designios de poeta. Aunque él insiste en expresar lo contrario, en 1910, en Lima. Antes de consentir la reedición de sus tres primeros poemarios, escribe:

Todo el cariño que abrigo por mis tradiciones o leyendas en prosa, sólo pueden igualarse al desapego que siento por mis renglones rimados. Si en los días de la mocedad pudo el amor propio alucinarme hasta el punto de creerme poeta, hoy, en horas de desencanto senil y de razonamiento frío, apenas si me tengo por mediano versificador (Palma, 1910: 5).

Demuestra su honestidad al referirse a su época de romántico. No niega su sentir, su posición o título de considerarse poeta, en su mocedad. Más bien, proporciona elementos para que cada lector decida por sí mismo donde situarlo, a la lectura de su obra y a sus experiencias de vida, lo que constituye una lealtad y confianza que lo retrata como un ser de excepción.

En otro espacio de tiempo, en 1853, a sus 20 años, encontramos al joven Ricardo Palma al servicio del Estado, como oficial tercero del Cuerpo Político de la Armada. Trabajo obtenido gracias a la confianza en sus cualidades personales de parte de amistades de alto rango, quienes lo protegen, y apoyan su demanda de ingreso a la Marina. La práctica cotidiana al interior de la Armada lo confronta al universo de valores institucionales, reglas y principios por los cuales se rige la Marina del Perú. Entre ellos, citamos la disciplina, la integridad, el patriotismo, el respeto, la

5 Colegio de Noel. El Colegio de Prengo y el Convictorio de San Carlos: https://www.biografiasyvidas.com/biografia/p/palma 
honestidad, la lealtad, la valentía, el honor y el compromiso ${ }^{6}$. El joven Palma, de espíritu romántico, se transforma: una recomendación por conducta responsable sirve de testimonio; es el justo premio por su acción después del naufragio del vapor Rímac, donde estaba comisionado ${ }^{7}$.

Sus actitudes y personalidad no pasan desapercibidas, hay otras conciencias que observan su desarrollo, sus posiciones sociales, políticas, revelaciones escritas $\mathrm{u}$ orales. Por lo expuesto, es contactado e invitado a hacer parte de otra hermandad. En julio de 1855 es iniciado como aprendiz en la logia Concordia Universal del Callao. Otros mundos se abren a sus interrogaciones. Ritos, símbolos, mitos y leyendas son parte de la historia de un ideal espiritual, amistoso y fraternal, al cual se adhiere y participa toda su vida. De esta manera, sigue las huellas de Bolívar, San Martín y O’Higgins, quienes, inspirados por el venezolano Francisco de Miranda, crean en Cádiz, hacia 1811, la logia Lautaro, cuyo objetivo principal era lograr la independencia de América del dominio español, y establecer un sistema republicano, unitario y unipersonal. Esos objetivos logran ser realidad, sin escatimar esfuerzos, y manteniendo entre ellos su juramento iniciático de unidad y solidaridad.

El reflejo de estas primeras miradas nos confirma la evolución personal de Ricardo Palma, inspirada por concretas experiencias en las dos hermandades que lo acogen y consolidan su personalidad. Si en la hermandad de la Marina fortifica su sentido de la disciplina, deber y honor patriótico en la hermandad de los tres puntos se reconoce como hermano de una familia universal. Y me pregunto si ¿no es esta precisamente su búsqueda interior: pertenecer a una unidad familiar, la cual

6 Principios y Valores institucionales: www.essup.edu.pe/principios.html

7 Oswaldo Holguín Callo. Apunte biobibliográfico de Ricardo Palma en www. cervantesvirtual.com/ricardo_palma/apunte_biobibliografico/ 
estuvo ausente durante su infancia y adolescencia? Dejo a cada uno la respuesta.

\section{Segunda mirada: Destierro. Amistades. Madurez creativa.}

La palabra no silencia la vida, son las amargas heridas las que cambian nuestros ecos. Son la toma de decisiones las que marcan, para bien o menos bien, nuestro destino. Y las raíces de toda acción se sitúan en las convicciones. Ver, reflexionar y actuar no es una quimera, es el resultado filosófico de quien, como Ricardo Palma, asume sus convicciones políticas y espirituales. Como, de igual manera, deberá asumir las consecuencias de su fracaso después de contribuir a la asonada militar contra el palacio presidencial, donde pernoctaba el general Ramón Castilla, en noviembre de 1860. En diciembre de ese mismo año, se embarca rumbo a Valparaíso. Comienza su primer destierro. Separado de su tierra, frente a remembranzas afectivas, la soledad, y con recursos económicos limitados, siente imperiosamente que debe rehacer su vida. El puerto de Valparaíso de esa época mostraba una actividad dinámica, gracias al libre comercio abierto después de la Independencia (1810) a países de América y Europa. Dicha bonanza atrajo una migración interna y en especial de jóvenes extranjeros en busca de un porvenir a sus inquietudes. Por calles y cerros del puerto se escuchaban los acentos de ingleses, irlandeses, franceses, vascos, italianos, etc. No fue difícil para el joven Palma integrarse a esta sociedad cosmopolita. Su elocuencia, cultura y aura personal, le atraen jóvenes amistades de la incipiente burguesía porteña y santiaguina. Destaca en estos encuentros, el escritor y abogado liberal José Victorino Lastarria ${ }^{8}$, quien,

8 José Victorino Lastarria, 1817-1888. Consultar en: www.memoriachilena. cl/602/w3-article-3 l 493html 
por experiencia, conocía bien las vicisitudes de un destierro. Lo había padecido en 1851, en la ciudad de Lima. Y cosas del destino, vuelve al Perú en 1862, pero esta vez como embajador. Lastarria, junto a personalidades de diferentes países, participó activamente en la Sociedad de Amigos de la Ilustración, establecida en Valparaíso desde 1859. El objetivo básico de esta organización era difundir los conocimientos en los ramos que tuvieran relación con las letras y las ciencias sociales. Al principio, la Sociedad editaba la Revista del Pacífico, como órgano de difusión. Pero al ser clausurada por orden del gobierno de Manuel Montt ${ }^{9}$, toma el relevo la Revista Sud América. Invitado Ricardo Palma a ser miembro activo de la Sociedad, sus notas y artículos comienzan a circular progresivamente en los diferentes medios sociales de Chile, Perú y el extranjero.

Otros destacados amigos del escritor en Valparaíso, y durante todo su tiempo de vida, fueron Guillermo y Alberto Blest Gana, descendientes de una familia humilde de origen irlandesa, instalados en Santiago a comienzos del siglo XIX. Su padre era médico, y había contribuido a fomentar su estudio y su enseñanza fundando la Escuela de Medicina en 1833. Las afinidades de Palma con Guillermo Blest Gana provienen de su condición de poeta y exponente de la literatura romántica, además de ser un prominente liberal, de inclinación radical y lector de Espronceda, Zorrilla, Byron, entre otros, que encendieron, al igual que en el sentimiento de Ricardo Palma, la llama romántica.

Con Alberto Blest Gana comparte la experiencia de la prosa. Alberto es considerado aún hoy, como uno de los más importantes novelistas sudamericanos del siglo XIX. Siguiendo el destino de difusión de las Tradiciones y escritos de Ricardo Palma; las novelas de Alberto son una lectura obligada en

9 Presidente de Chile durante dos períodos: 1851 a 1856 y 1856 a 1861. 
los liceos de la educación chilena ${ }^{10}$. Ambos estilos literarios, los de Palma y Alberto Blest Gana, coinciden en destacar el costumbrismo, su visión lingüística de expresiones populares y la memoria social. Al amparo de estas experiencias, poetas y escritores maduraron sus obras. Ricardo Palma publicó en Valparaíso siete tradiciones, poesía y reflexiones que tituló Anales de la Inquisición en Lima. El destierro no ha sido en vano, Palma es reconocido como intelectual y escritor en un amplio ámbito hispanoamericano, y a su regreso a Lima, después de ser amnistiado, en agosto de 1863. Resaltamos que consigo trae no solo sus creaciones literarias, sino otro valor universal, ético y moral, como son los profundos lazos de la amistad. Estamos convencidos de que una amistad sincera y perdurable no tiene color, ni horarios, ni días en los calendarios. Existe porque el otro existe, y es respuesta compartida entre vivencias alegres o tristes. La sabiduría se adquiere en el darse, y aprender a recibir lo humano al ojo de lo divino. Tener un buen amigo es mejor que tener dinero, nos aconseja la tradición popular. Ricardo Palma lo sabía por experiencia propia. Y en su acción, entregó la amistad con honesta generosidad.

\section{Tercera mirada: Viajes. Biblioteca Nacional. Academias.}

Todo regreso implica recomenzar, pero no con las mismas experiencias de la partida sino con una mirada más profunda, donde lo adquirido durante la ausencia ayuda a redefinir los nuevos desafíos de la existencia. No podía ser de otra manera para nuestro ilustre escritor. En Lima, sus importantes conexiones sociales y políticas colaboran en su nombramiento como cónsul

10 Se destacan: Martín Rivas (1862), El loco estero (1909), El ideal de un calavera (1875), Los transplantados (1905). Es necesario decir que Alberto Blest Gana nació en Santiago (1930) y falleció en París (1920). Sus restos permanecen enterrados en el famoso cementerio Père Lachaise de la capital francesa. 
del Perú en el Puerto de Pará (Belem), Brasil, en los albores de 1864. Pero, sorpresivamente, antes de asumir su cargo, solicita una licencia y viaja a Europa, visitando Londres, Bruselas, París, Italia y otras ciudades. Cumplía de esta forma un gran sueño: descubrir el Viejo Continente, cuna de románticos, de escritores y poetas, quienes le habían influenciado en su incipiente formación literaria. Imaginamos su viva emoción al caminar por las mismas calles que recorrían Víctor Hugo, Baudelaire o Lamartine. Y constatar con asombro la reorganización urbanística de la ciudad, decretada por Napoleón III ${ }^{11}$, cuyas obras fueron dirigidas por el barón Haussmann. Anchas avenidas, edificios, paseos, plazas, monumentos, reemplazan los viejos barrios que serán reconstruidos en la llamada periferia parisina y que aún existen. Detrás de este proyecto, resalta la ambición de Napoleón III de convertir París en una gran ciudad del comercio e intelecto cosmopolita. No alcanzó a ver realizado su sueño, murió desterrado en Inglaterra en enero de 1873.

Solo algunas referencias sumarias hemos encontrado como fuentes bibliográficas de este viaje de Ricardo Palma, y su estadía en París. Es una labor de investigación que me prometo realiza dado mi creciente interés por la vida y obra del autor de Tradiciones peruanas. Por hoy, continuemos su itinerario. $\mathrm{Al}$ regresar a su país, en 1865 , serias decisiones y deberes lo esperan. Entre ellos, colocarse al servicio del gobierno ante el conflicto con España. Participa activamente en el Combate del Callao $^{12}$, como asistente del secretario de Guerra José Gálvez, quien muere en combate. Un año después, apoya la sublevación del coronel José Balta, lo que le vale la cárcel y un segundo destierro. Esta vez en Guayaquil. Tiempo después, por sufragio

11 Carlos Luis Napoleón Bonaparte, París 1808 / Inglaterra 1873. Fue Presidente de la República en 1848/1852. Enseguida, Emperador de Francia entre 1852 y 1870 .

12 Mayor información en : https://historiaperuana.pe/periodo-independiente/ republica/guerra-con-espana/ 
universal, Balta gana las elecciones y es elegido presidente en $1868^{13}$. No olvida a su colaborador más cercano y lo nombra su secretario personal. Ricardo Palma es encargado de las importantes relaciones con la prensa escrita, dada sus relaciones y experiencias. En paralelo, continúa participando en política, siendo elegido senador por la provincia de Loreto. Pero el destino le tenía reservada otras amargas sorpresas que cambiarán drásticamente su vida. El presidente José Balta es asesinado por un grupo de militares sublevados no conformes con su gestión de gobierno, esto ocurría en julio de 1872. La forma y el fondo del crimen conmocionan la sensibilidad del escritor, quien decide no volver a actuar en la vida política del Perú y dedicarse por entero a la investigación histórica, la literatura y su familia. Fueron decisiones no fáciles de asumir, pero importantes para el futuro no solo de sus escritos, crónicas, artículos e investigaciones, sino también para el definitivo reconocimiento internacional de nuevas generaciones de escritores peruanos. El año 1878 es significativo para su singular trayectoria creativa y para las letras del Perú: es nombrado Miembro Correspondiente de la Academia Española de la Lengua ${ }^{14}$.

No alcanzó a disfrutar su alegría. Al año siguiente, 1879, se desencadena el conflicto bélico de la Guerra del Pacífico. Sufre directamente la posterior ocupación del ejército chileno en Lima al ser quemado su hogar en Miraflores, dentro del cual abrigaba su valiosa biblioteca. Además de manuscritos y apuntes inéditos ${ }^{15}$. Hago una pausa para colocarme en su lugar. Me digo que no existe ninguna excusa válida frente a la ignominia de una guerra, cualesquiera sean los motivos. Nada puede valer

13 José Balta. Lima 1816/1872. Militar y político peruano.

14 Roy L. Tanner, Ricardo Palma, neólogo por excelencia. Consultado en : www. cervantesvirtual.com/obra-visor/ricardo-palma-nelogo-por-excelencia

15 Mayor información en: www.cervantesvirtual.com/obra-visor/ricardo-palmaen-la-obra-de-porras-apuntes-y-bibiografia-0/htlm/0 16b3958-82b2-1 I df-acc7002185 ce6064 
más que una vida humana. Y más que la siembra de la razón frente a exacerbados patriotismos, que en general esconden mezquinos intereses económicos. Comprendo igualmente lo difícil que es el perdonar, en particular, cuando se han perdido seres queridos, y se sufren exilios. Mi posición ha sido y es: decir no al olvido, porque olvidar es no haber vivido.

Las acciones de Ricardo Palma, terminada la guerra, demuestran una vez más su entereza. En 1883, acepta la dirección de la Biblioteca Nacional del Perú ofrecida por el presidente Iglesias. Y logra reinaugurarla en 1884 gracias a donaciones en el ámbito nacional, además de países y personalidades del mundo. Esta acción le significa el apelativo de El bibliotecario mendigo. Asume su sobrenombre con dignidad. Pobres pero dignos, nos recuerda la memoria tradicional de nuestros pueblos. Palma no escatimó contactos y relaciones personales para solicitar libros Sabía por experiencia que todo desarrollo personal requiere imaginación, la cual unida a la inteligencia y perseverancia educan carácteres con nobleza de espíritu y el buen sentido de la libertad. Durante 29 años fue director de la Biblioteca Nacional.

Otro de sus importantes logros fue la creación de la Academia Peruana de la Lengua, en mayo de 1887. Responde así al patrocinio de la Real Academia Española que confía en su discernimiento y su innegable capacidad de organización para cimentar las raíces de un organismo que hoy, a sus 130 años de existencia, continúa siendo el más representativo de las letras peruanas, al interior y exterior del país. Ricardo Palma, hasta sus últimos días, aportó conocimientos, léxicos y particularidades idiomáticas, que conforman la riqueza del lenguaje plurilingüista del Perú, en su gran mayoría, aceptados por todas las academias hispanoamericanas. 


\section{A modo de conclusión}

Sembrar es una de las palabras esenciales para comprender la cruzada de un iluminado poeta, escritor, periodista y actor social como lo fue don Ricardo Palma. Atreverse a sembrar la confianza para alejar los prejuicios. Atreverse a sembrar los principios de toda fe con respeto, sin molestar o dejar de lado a nadie. Ver, reflexionar y actuar ante un mundo de sutiles apariencias, de arrogancias y vanidades sin futuro. Atreverse a ser un simple resplandor entre las tinieblas. En especial, para aquellos que desconfían, agravian, perjudican, sin conocer el verdadero reflejo y gracia de las palabras amigar, fraternizar, amar. Don Ricardo lo había comprendido. Y con una ardiente paciencia fue sorteando escollos para sembrar los ecos de un retorno a las raíces, de lo que conocemos como peruanidad. Sus escritos y estilo sostienen las raíces expresivas de su pueblo. En él se mezclan tres culturas: indígena, española y negra, lo que de por sí forman parte de una gran riqueza identitaria y cultural.

Podemos estar de acuerdo o no con su quehacer político o literario. Lo importante es el sentido humano que, como destino, se refleja en su accionar; lo que conlleva, en sí mismo, encontrar la raíz de una revolución permanente. Es el ser en las innumerables preguntas sobre la existencia quien se atreve a formular respuestas. Y ellas provienen de sus diferentes percepciones naturales o metafísicas. Porque nada es indiferente al sentir de los sentimientos. El verbo es la raíz del lenguaje; el escritor y los artistas, los representantes de sus ecos. Su labor es de profundizar sobre la mirada humana. En sus símbolos, mitos y leyendas. En las expresiones creativas de todo arte. En la evolución del compartir la existencia. Por ello, consideramos esencial los esfuerzos de toda persona que lucha por construir sociedades justas, solidarias, donde se respeten valores que hacen del ser humano un ciudadano de la madre tierra, un ciudadano de la humanidad. 
Como los antiguos sabios de la tribu, Ricardo Palma poseía una mirada más larga. Y la proyectó en su constante compromiso y acción, sea política, literaria o familiar. En esa continua proyección de existencia, contra viento y marea sustentó valores de justicia, igualdad, libertad, fraternidad, que edifican, sin tiempo, el meritorio reconocimiento de ser un personaje fuera de lo común, cuya obra y perfiles de vida han logrado trascender al tiempo. Me atrevo a definir una personal conclusión: ante todo, sostengo que Ricardo Palma llevaba en sí el aura y espíritu de un poeta. Era el prototipo de los bardos que luchan toda una vida por sus ideales, y en construir su derecho a soñar, porque están convencidos que una sociedad que no sueña es una sociedad muerta. El hermano mayor, el primogénito, y en la tradición, aquel que debe asumir responsabilidades de la familia, cuidar hermanos, ser ejemplo como padre, en caso de ausencia del verdadero. Este poeta, mi hermano mayor, que me remite al pasado y a mis propias reminiscencias, vivió sus últimos años en la tranquilidad de su descendencia, el cariño de su familia, y el respeto de quienes lo reconocieron como maestro. Y me pregunto si ino es esto precisamente lo que deseamos una mayoría de personas: cultivar valores que sustenten una existencia digna, de concordia y en paz con nosotros y el mundo? El legado tangible de Ricardo Palma reposa principalmente en estos ideales y en sus obras, las que nos invitan a continuar perseverando en la siembra de valores de existencia que recuerden y dignifiquen nuestra condición humana.

\section{Bibliográfica}

Brodsky, J. (2017) Del dolor y la razón. Recuperado de Diarios de Resistencia. Consultado en: http://diariosderesistencia.blogspot. pe/2017/02/del-dolor-y-la-razon.html 
Holguín Callo, O. (s/f). Apunte biobibliográfico de Ricardo Palma. Consultado en: www.cervantesvirtual.com/portales/ricardo_palma/ apunte_biobibliografico/

Palma, R. (s/f) Verbos y gerundios, 1870-1878. Consultado en: es.diarioinca.com/2008/10/la-poesia-ricardo-palma.html

Palma, R. (1910) Poesía Completa. Barcelona: Maucci; Buenos Aires, Maucci Hermanos.

Tanner, Roy L. (s/f) Ricardo Palma, neólogo por excelencia. Consultado en: www.cervantesvirtual.com/obra-visor/ricardo-palma-nelogo-porexcelencia

Recibido el 15 de enero del 2018 Aceptado el 10 de abril del 2018 